\title{
Angiotensin II inhibits chemokine CCL5 expression in vascular smooth muscle cells from spontaneously hypertensive rats
}

\author{
Young Hyun Yun ${ }^{1}$, Hye Young Kim², Byung Soo $\mathrm{Do}^{3}$ and Hee Sun Kim²
}

Angiotensin II (Ang II) exerts some of its effects on the vasculature by stimulating chemokines and 12-lipoxygenase (12-LO). In addition, a high expression of chemokines by Ang II has been observed in vascular smooth muscle cells (VSMCs) in spontaneously hypertensive rats (SHR). In this study, the action mechanism of Ang II on CCL5 expression in SHR VSMCs was examined. Expression of CCL5 in SHR thoracic aorta tissues and VSMCs was lower than that in normotensive Wistar-Kyoto rats (WKY) thoracic aorta tissues and VSMCs. Moreover, Ang II inhibited CCL5 expression in SHR VSMCs, but not in WKY VSMCs. Inhibition of CCL5 by Ang II was mediated by both Ang II subtype 1 receptor $\left(A T_{1} R\right)$ and subtype 2 receptor $\left(A T_{2} R\right)$ activation in SHR VSMCs. However, Ang II did not inhibit CCL5 expression in SHR VSMCs that were transfected with 12-LO small interfering RNA. In addition, 12-LO metabolite, 12(S)-hydroxyeicosatetraenoic acid (HETE) inhibited CCL5 mRNA expression in SHR VSMCs. The expression of Ang II-induced 12-LO was also blocked by both $\mathrm{AT}_{1} \mathrm{R}$ and $\mathrm{AT}_{2} \mathrm{R}$ inhibitors. Mitogen-activated protein (MAP) kinase, extracellular signal-regulated kinase (ERK)1/2, p38 and Jun N-terminal kinase pathways all mediated the inhibitory action of Ang II on CCL5 expression in SHR VSMCs. Taken together, the inhibitory action of Ang II on CCL5 expression was shown to be mediated by the 12-LO pathway through the activation of both of $A T_{1} R$ and $A T_{2} R$ and this process was associated with MAP kinase pathways in SHR VSMCs. This result suggests that upregulation of 12-LO by Ang II leads to the downregulation of CCL5 expression in SHR VSMCs.

Hypertension Research (2011) 34, 1313-1320; doi:10.1038/hr.2011.132; published online 4 August 2011

Keywords: angiotensin II; CCL5; 12-lipoxygenase; vascular smooth muscle cell

\section{INTRODUCTION}

Angiotensin II (Ang II) is a potent vasoconstrictor and blood pressure regulator. In addition, Ang II has been shown to function as a potential mediator of inflammation and was reported to exert some of its effects on the vasculature by stimulating chemokines. ${ }^{1-7}$

Chemokines have an important role in Ang II-induced vascular hypertension, ${ }^{8-11}$ and controlling chemokine production is important for regulating inflammatory reactions in hypertensive vascular walls. In fact, the suppression of chemokine-induced inflammatory cell infiltration has been shown to ameliorate hypertension in experimental animal models. ${ }^{12-15}$ Thus, up- and downregulation of chemokines has been considered a therapeutic strategy for blocking disease development or progress, including hypertension. ${ }^{16}$ However, the molecular and cellular mechanisms of most chemokines are not yet clearly understood.

The proinflammatory chemokine CCL5 (regulated upon activation, normally T-cell expressed and presumably secreted; RANTES) is a potent chemoattractant for monocytes/macrophages and memory $\mathrm{T}$ lymphocytes, and its production has been described in various cell types, including human aortic vascular smooth muscle cells (VSMCs) ${ }^{17,18}$ It has a functional role in acute and chronic inflammatory responses in atherosclerosis, renal disease progression and vascular wall remodeling in pulmonary arterial hypertension., ${ }^{2,3,19,20}$ However, CCL5 downregulates LPS-induced cytokines expression in human peripheral blood monocytes, ${ }^{21}$ and has a possible neuroprotective role in the brains of patients with Alzheimer's disease. ${ }^{22}$

Some chemokines upregulate Ang II-induced hypertension and a high expression of chemokines has been detected in VSMCs isolated from spontaneously hypertensive rats (SHR). ${ }^{8-11}$ The increase of chemokine CCL2 or CXCL8 expression by Ang II has been shown in SHR VSMCs and rat glomerular endothelial cells. $.6,8,9,23,24$ The increase of CCL5 expression by Ang II has been also demonstrated in rat glomerular endothelial cells and the renal cortex. ${ }^{2,3}$ However, CCL5 has been shown to inhibit the expression of Ang II-induced 12-lipoxygenase (LO), a hypertensive modulator in SHR VSMCs. ${ }^{25}$

Although the relationships between Ang II and some chemokines or chemokine receptors, including CCL2 and CXCL8, in renal disease and vascular hypertension have been studied, ${ }^{4,8,9,23,24}$ the relationship

${ }^{1}$ Department of Emergency Medicine, College of Medicine, Dong-A University, Pusan, South Korea; ${ }^{2}$ Department of Microbiology, College of Medicine, Yeungnam University, Daegu, South Korea and ${ }^{3}$ Department of Emergency Medicine, College of Medicine, Yeungnam University, Daegu, South Korea 
between Ang II and CCL5 has not yet been characterized and little is known in SHR VSMCs. Therefore, as a first step to understand the relationship between Ang II and CCL5 in Ang II-induced vascular hypertension, the effect of Ang II on CCL5 expression was evaluated in SHR VSMCs.

\section{METHODS}

\section{Reagent}

Trizol reagent for total RNA isolation was purchased from Invitrogen (Carlsbad, CA, USA). Dulbecco's phosphate-buffered saline, Dulbecco's modified Eagle's medium, penicillin-streptomycin and fetal bovine serum were purchased from Gibco/BRL (Life Technologies, Gaithersburg, MD, USA). Ang II was obtained from Calbiochem (San Diego, CA, USA). Losartan was obtained from MSD (Delaware, MD, USA). PD123,319 was obtained from Sigma Chemical (St Louis, MO, USA). LightCycler FastStart DNA SYBR Green I Mix was obtained from Roche (Mannheim, Germany). Bay11-7082 was obtained from Merck (Merck KGaA, Darmstadt, Germany). Baicalein was obtained from Sigma-Aldrich. 12(S)-HETE was purchased from Cayman Chemical (Ann Arbor, MI, USA). PD98059, PD169316 and SP600125 were purchased from Merck. The primer sequences for CCL5, 12-LO, $A_{1} R, A_{2} R$ and $\beta$-actin were purchased from Bioneer technology (Daejeon, South Korea). The rat $\mathrm{AT}_{1} \mathrm{R}$ small interfering RNA (siRNA), $\mathrm{AT}_{2} \mathrm{R}$ siRNA, 12-LO siRNA, ERK1 siRNA, ERK2 siRNA and Jun N-terminal kinase (JNK) siRNA sequences were purchased from Bioneer technology. Rat p38 siRNA sequence was purchased from Invitrogen. All other reagents were pure-grade commercial preparations.

\section{Experimental animals}

Specific pathogen-free male inbred SHR or normotensive Wistar-Kyoto rats (WKY), 12-16 weeks of age, were purchased from Japan SLC (Shizuka, Japan). All experimental animals received autoclaved food and bedding to minimize exposure to viral and/or microbial pathogens. Rats were cared for in accordance with the Guide for the Care and Use of Experimental Animals of Yeungnam Medical Center.

\section{Immunohistochemistry}

Aortic cross-sections were immunohistochemically stained for CCL5. To assess CCL5 protein expression, slides fixed with aortic cross-sections were treated with pepsin for antigen retrieval, and endogenous peroxidase was blocked with $3 \% \mathrm{H}_{2} \mathrm{O}_{2}$. After blocking with normal blocking serum for $30 \mathrm{~min}$ at room temperature (RT), sections were incubated with the anti-CCL5 antibody (1:50) for $1 \mathrm{~h}$ at RT and HRP-conjugated rabbit anti-mouse IgG antibody for $30 \mathrm{~min}$ at RT. The sections were then developed with the 3,3'-diaminobenzidine substrate-chromogen system for $5 \mathrm{~min}$ at RT.

\section{VSMCs preparation}

VSMCs were obtained from the thoracic aortas of 12-16 week-old-male SHR and WKY using the explant method as described by Kim et al. ${ }^{8}$ VSMCs were cultured in Dulbecco's modified Eagle's medium, which was supplemented with $10 \%$ fetal bovine serum and $1 \%$ penicillin-streptomycin. Cells were detached with $0.25 \%$ trypsin/EDTA and seeded onto $75-\mathrm{cm}^{2}$ tissue culture flasks at a density of $10^{5} \mathrm{cells} \mathrm{ml}^{-1}$. All experiments were conducted between cell passages 3-7. Before stimulation, 95\%-confluent VSMCs were serumstarved overnight by incubating in Dulbecco's modified Eagle's medium with $0.1 \%$ fetal bovine serum. Cell cultures were incubated in a humidified incubator at $37^{\circ} \mathrm{C}$ and $5 \% \mathrm{CO}_{2}$ in the presence or absence of stimuli for the indicated times.

\section{Preparation of total RNA, reverse transcriptase-PCR and real-time PCR}

Total RNA was extracted using the Trizol reagent according to the manufacturer's instructions. The quantity of total RNA obtained was determined by measuring the optical density at 260 and $280 \mathrm{~nm}$.

A total of $1 \mu \mathrm{g}$ RNA per sample was reverse transcribed using Moloney murine leukemia virus reverse transcriptase (Perkin Elmer, Norwalk, CT, USA) and oligo dT priming at $42^{\circ} \mathrm{C}$ for $15 \mathrm{~min}$ according to the manufacturer's instruction. Amplification with specific primers was performed in a Gene Amp PCR system 9600 (Perkin Elmer) for 35 cycles with a $30 \mathrm{~s} / 94^{\circ} \mathrm{C}$ denaturation, $30 \mathrm{~s} / 62{ }^{\circ} \mathrm{C}$ annealing, $1 \mathrm{~min} / 72{ }^{\circ} \mathrm{C}$ extension profile in the case of CCL5; for 35 cycles with a $20 \mathrm{~s} / 94{ }^{\circ} \mathrm{C}$ denaturation, $10 \mathrm{~s} / 55^{\circ} \mathrm{C}$ annealing, $40 \mathrm{~s} / 72{ }^{\circ} \mathrm{C}$ extension profile in the case of $\mathrm{AT}_{1} \mathrm{R}$; for 35 cycles with a $20 \mathrm{~s} / 94^{\circ} \mathrm{C}$ denaturation, $10 \mathrm{~s} /$ $60{ }^{\circ} \mathrm{C}$ annealing, $40 \mathrm{~s} / 72{ }^{\circ} \mathrm{C}$ extension profile in the case of $\mathrm{AT}_{2} \mathrm{R}$; for 30 cycles with a $20 \mathrm{~s} / 95^{\circ} \mathrm{C}$ denaturation, $30 \mathrm{~s} / 60^{\circ} \mathrm{C}$ annealing, $30 \mathrm{~s} / 72{ }^{\circ} \mathrm{C}$ extension profile in the case of $\beta$-actin. The mRNA of the housekeeping gene $\beta$-actin was amplified and used as an internal quality standard. Amplified products were electrophoresed on $1.5-2 \%$ agarose gel and stained with $0.5 \mu \mathrm{g} \mathrm{ml}^{-1}$ ethidium bromide. The primer sequences were as follows: $\beta$-actin (101 bp) sense, 5'-TACTGCCCTGGCTCCTAGCA-3', antisense, 5'-TGGACAGTGAG GCCAGGATAG-3'; CCL5 (110 bp) sense, 5'-CGTGAAGGAGTATTTTTACACC AGC-3', antisense, 5'-CTTGAACCCACTTCTTCTCTGGG-3'; AT $_{1}$ R (445 bp) sense, $5^{\prime}$-CACCTATGTAAGATCGCTTC- ${ }^{\prime}$, antisense, $5^{\prime}$-GCACAATCGCCAT AATTATCC-3'; AT $_{2} \mathrm{R}$ (65 bp) sense, 5'-CCGTGACCAAGTCTTGAAGATG-3', antisense, $5^{\prime}$-AGGGAAGCCAGCAAATGATG- $3^{\prime}$.

12-LO, CCL 5 was amplified by real-time PCR using the LightCycler (Roche). RNA was reverse transcribed to cDNA from $1 \mu \mathrm{g}$ of total RNA and then subjected to real-time PCR. PCR was performed in triplicate. The total PCR volume was $20 \mu \mathrm{l}$ and the PCR consisted of LightCycler FastStart DNA SYBR Green I mix (Roche), primer and $2 \mu \mathrm{l}$ of cDNA. Before PCR amplification, the mixture was incubated at $95^{\circ} \mathrm{C}$ for $10 \mathrm{~min}$, and the amplification step consisted of 45 cycles of denaturation $\left(10 \mathrm{~s}\right.$ at $95^{\circ} \mathrm{C}$ ), annealing ( $5 \mathrm{~s}$ at the primerappropriate temperature) and extension $\left(10 \mathrm{~s}\right.$ at $\left.72^{\circ} \mathrm{C}\right)$ with fluorescence detection at $72{ }^{\circ} \mathrm{C}$ after each cycle. After the final cycle, melting point analyses of all samples were performed over a temperature range of $65-95^{\circ} \mathrm{C}$ with continuous fluorescence detection. $\beta$-actin expression levels were used for sample normalization. Results for each gene were expressed as the relative expression level compared with $\beta$-actin. The primers used for PCR were as follows: 12-LO (312 bp) sense, 5'-TGGGGCAACTGGAAGG-3', antisense, 5'-AGAGCGCTTCAGCACCAT-3'; CCL5 (110 bp) sense, 5'-CGTGAAGGAGT ATTTTTACACCAGC-3', antisense, 5'-CTTGAACCCACTTCTTCTCTGGG-3'; $\beta$-actin (101 bp) sense, $5^{\prime}$-TACTGCCCTGGCTCCTAGCA-3', antisense, $5^{\prime}$-TGGACAGTGAGGCCAGGATAG- $3^{\prime}$. The levels of 12-LO and CCL5 mRNA were determined by comparing experimental levels to standard curves and were expressed as relative fold expressions.

\section{Electrophoretic mobility shift assay}

Cells were washed three times with cold phosphate-buffered saline, then scraped and harvested by centrifugation. Cell pellets were resuspended and incubated on ice for $15 \mathrm{~min}$ in $400 \mu \mathrm{l}$ of hypotonic buffer A $\left(10 \mathrm{mmoll}^{-1}\right.$ HEPES, $10 \mathrm{mmoll}^{-1} \mathrm{KCl}, 1.5 \mathrm{mmoll}^{-1} \mathrm{MgCl}_{2}, 0.5 \mathrm{mmoll}^{-1}$ Dithiothreitol , $0.1 \mathrm{mmoll}^{-1}$ phenylmethylsulfonyl fluoride, $10 \mu \mathrm{g} \mathrm{ml}^{-1}$ pepstatin, $10 \mu \mathrm{g} \mathrm{ml}^{-1}$ leupeptin, $10 \mu \mathrm{g} \mathrm{ml}^{-1}$ autipain and $10 \mu \mathrm{g} \mathrm{ml}^{-1}$ aprotinin). Nonidet P-40 was then added to a final concentration of $2.5 \%$, and the cells were vortexed for $10 \mathrm{~s}$. Nuclei were separated from the cytosol by centrifugation at $12000 \mathrm{~g}$ for $15 \mathrm{~s}$. Pellets were resuspended in $40 \mu \mathrm{l}$ of hypotonic buffer C $\left(20 \mathrm{mmoll}^{-1}\right.$ HEPES, $25 \%$ glycerol, $0.4 \mathrm{moll}^{-1} \mathrm{NaCl}, 1 \mathrm{mmoll}^{-1}$ EDTA, $1 \mathrm{mmoll}^{-1}$ ethylene glycol tetraacetic acid, $0.5 \mathrm{mmoll}^{-1}$ Dithiothreitol , $0.1 \mathrm{mmoll}^{-1}$ phenylmethylsulfonyl fluoride, $10 \mu \mathrm{g} \mathrm{ml}^{-1}$ pepstatin, $10 \mu \mathrm{g} \mathrm{ml}^{-1}$ leupeptin, $10 \mu \mathrm{g} \mathrm{ml}^{-1}$ autipain and $10 \mu \mathrm{g} \mathrm{ml}^{-1}$ aprotinin). Samples were sonicated for $2-3 \mathrm{~s}$, then centrifuged for $10 \mathrm{~min}$ at $4{ }^{\circ} \mathrm{C}$. The nuclear protein concentration was measured using the Bradford assay (Bio-Rad, Richmond, CA, USA). The consensus sequence of the NF- $\kappa \beta$ DNA binding site (5'-AGTTGAGGGGACTTTAGGC- $3^{\prime}$ ) (sc-2505; Santa Cruz Biotechnology, Santa Cruz, CA, USA) was labeled with $\left(\alpha-{ }^{32} \mathrm{P}\right) \mathrm{dCTP}$ using a random-primed DNA labeling kit (Roche). The mutant $N F-\kappa \beta$ binding sequence was identical to sc-2505 except for a ' $G$ ' $\rightarrow$ ' $C$ ' substitution in the NF- $\kappa \beta$ DNA binding motif (sc-2511; Santa Cruz Biotechnology). The labeled DNA was purified over a S-200 HR column (Pharmacia, Piscataway, NJ, USA) to remove unbound nucleotides. Nuclear protein extracts were incubated at RT for $20 \mathrm{~min}$ with $\sim 50000$ c.p.m. of labeled oligonucleotides that were suspended in a binding buffer $\left(200 \mathrm{mmoll}^{-1}\right.$ HEPES, $500 \mathrm{mmoll}^{-1} \mathrm{KCl}, 10 \mathrm{mmoll}^{-1}$ EDTA, $50 \%$ glycerol, $10 \mathrm{mmoll}^{-1}$ Dithiothreitol, $1 \mathrm{mg} \mathrm{ml}^{-1} \mathrm{BSA}$ and $1 \mu \mathrm{g} \mu \mathrm{l}^{-1}$ poly (dI-dC)). Following this incubation step, 
the samples were resolved on $4 \%$ polyacrylamide gels at $140 \mathrm{~V}$ and exposed to film.

\section{Small interfering RNA}

VSMCs were plated on 24-well plates and grown to $90 \%$ confluence. VSMCs were then transfected with AT2R siRNA oligomers $\left(50 \mathrm{nmoll}^{-1}\right)$ using lipofectamine 2000 in accordance with the manufacturer's instructions. After $24 \mathrm{~h}$ of incubation, VSMCs were placed in growth medium for $24 \mathrm{~h}$ before the experiments. Cells were then cultured in the presence or absence of stimuli for $4 \mathrm{~h}$. The sense and antisense oligonucleotides used in these experiments were as follows: $\mathrm{AT}_{1} \mathrm{R}$ siRNA sense, 5'-GUCACUGUUACUACACCUA-3', antisense, 5'-UAGGUGUAGUAACAGUGAC-3'; AT $_{2} \mathrm{R}$ siRNA sense, 5'-GAGUGUUGAUAG GUACCAA-3', antisense, 5'-UUGGUACCUAUCAACACUC-3'; 12-LO siRNA sense, $5^{\prime}$-GUGUGUGACUAUGUUCCAA- $3^{\prime}$, antisense, 5'-UUGGAACAUAG UCACACAC-3'; ERK1 siRNA sense, 5'-CUAUGAUCCGACAGAUGAA-3', antisense, 5'-UUCAUCUGUCGGAUCAUAG-3'; ERK2 siRNA sense, 5'-CAGG AAAGCAUUACCUUGA-3', antisense, 5'-UCAAGGUAAUGCUUUCCUG-3'; JNK siRNA sense, 5'-GAGCAAAAGCAAGGUAGAU-3', antisense, 5'-AUCUA CCUUGCUUUUGCUC- $3^{\prime}$; p 38 siRNA sense, $5^{\prime}$-UACAUUUGCGAAGUUC

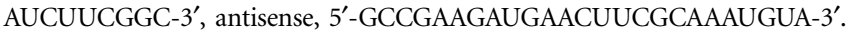

\section{Statistical analysis}

Results were expressed as means \pm s.e.m. from at least three or four independent experiments. For comparisons between multiple groups, statistical significance was determined by the Mann-Whitney test using SPSS version 17.0.

\section{RESULTS}

Ang II suppresses chemokine CCL5 expression in SHR VSMCs

First, CCL5 expression in SHR and WKY thoracic aorta tissues and VSMCs was examined. Expression of CCL5 in SHR thoracic aorta tissues and VSMCs was lower than that in WKY thoracic aorta tissues and VSMCs (Figure 1a). The expression of CCL5 mRNA by Ang II was then examined in SHR and WKY VSMCs. Ang II inhibited CCL5 mRNA expression in SHR VSMCs, but did not inhibit CCL5 expression in WKY VSMCs (Figure 1b). A decreased CCL5 level was also detected in SHR VSMCs that had been treated with Ang II (100 nM) after a reaction time of 1 and $4 \mathrm{~h}$ (Figure 1c). The time course of Ang II-induced CCL5 inhibition was then determined in SHR VSMCs over a $0-16$-h time period. In this experiment, inhibition of CCL5 mRNA induced by Ang II was detected $1 \mathrm{~h}$ after treatment and was sustained for up to $8 \mathrm{~h}$ after treatment and this effect disappeared at $16 \mathrm{~h}$. The inhibition levels of CCL5 by Ang II were almost same from $1 \mathrm{~h}$ after treatment to $8 \mathrm{~h}$ after treatment (Figure 2a). The dose response of Ang II-induced CCL5 inhibition was also observed. Inhibition of CCL5 expression was initially detected from at a Ang II concentration of $10 \mathrm{~nm}$ Ang II. Although the inhibition by Ang II was shown in all three concentrations of 10, 100 and $1000 \mathrm{~nm}$, there were no statistical differences among these concentrations (Figure 2b).

To understand the nature of the inhibitory effect of Ang II on CCL5 expression in SHR VSMCs, the role of NF- $\kappa \beta$ activation was examined. Bay11-7082 is known to selectively block the phosphorylation of $\mathrm{I} \kappa \mathrm{B} \alpha$; thus, preventing activation and nuclear translocation of NF- $\kappa \mathrm{B}$. Real-time PCR, (enzyme-linked immunosorbent assay) and electrophoretic mobility shift assay were performed on VSMCs after they had been treated or not treated with Ang II (100 nM) in the absence or presence of Bay11-7082 (10 $\mu \mathrm{M})$ for $1 \mathrm{~h}$. Bay11-7082 prevented Ang II from inhibiting CCL5 mRNA expression, and the protein levels of CCL5 correlated to the mRNA levels (Figure 2c, upper). Increased NF$\kappa \beta$ activity in SHR VSMCs treated with Ang II alone disappeared in cells treated with Ang II and Bay11-7082 (Figure 2c, lower).

To examine whether inhibition of CCL5 expression by Ang II was mediated by the Ang II subtype 1 receptor $\left(A_{1} R\right)$ or subtype 2 receptor $\left(\mathrm{AT}_{2} \mathrm{R}\right)$, SHR VSMCs were treated or not treated with Ang II $(100 \mathrm{nM})$ in the presence or absence of an antagonist of the $A T_{1} R$, losartan $(10 \mu \mathrm{M})$ or an antagonist of the $\mathrm{AT}_{2} \mathrm{R}, \mathrm{PD} 123,319(10 \mu \mathrm{M})$ for 1 or $4 \mathrm{~h}$, and the total RNAs were analyzed by reverse transcriptasePCR. Protein levels of CCL5 in the cell supernatants were evaluated by (enzyme-linked immunosorbent assay). The inhibitory effect of Ang II on CCL5 mRNA expression was not observed in the presence of both
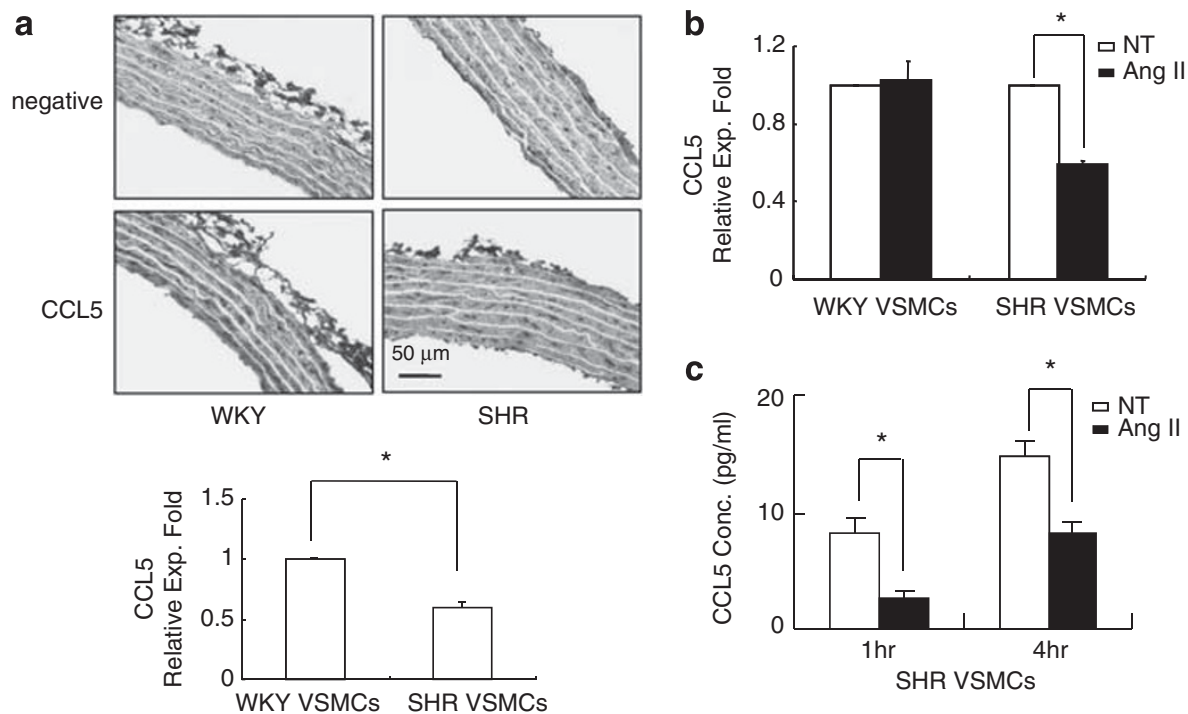

Figure 1 Expression of CCL5 in SHR and WKY thoracic aorta tissues and VSMCs, and the inhibitory effect of Ang II on CCL5 expression in SHR VSMCs. (a) Aortic cross-sections were immunohistochemically stained for CCL5. Original magnification was $\times 200$ (Zeiss microscope, Oberkochen, Germany). After total RNAs were isolated from SHR or WKY VSMCs, real-time PCR was performed. Bars represent means \pm s.e.m. from three independent experiments. ${ }^{*} P<0.05$ vs. WKY VSMCs. (b) SHR and WKY VSMCs were treated or not treated (NT) with Ang II $\left(0.1 \mu \mathrm{mol} \mathrm{I}^{-1}\right)$ for $1 \mathrm{~h}$. After total RNAs were isolated, realtime PCR was performed. ${ }^{*} P<0.05$ vs. untreated SHR VSMCs. (c) SHR VSMCs were treated or NT with Ang $I I\left(0.1 \mu \mathrm{mol} \mathrm{I}^{-1}\right)$ for 1 or $4 \mathrm{~h}$. After cell supernatants were isolated, (enzyme-linked immunosorbent assay) was performed. Bars represent means \pm s.e.m. from three independent experiments. ${ }^{*} P<0.05$ vs. untreated SHR VSMCs. A full color version of this figure is available at the Hypertension Research journal online. 

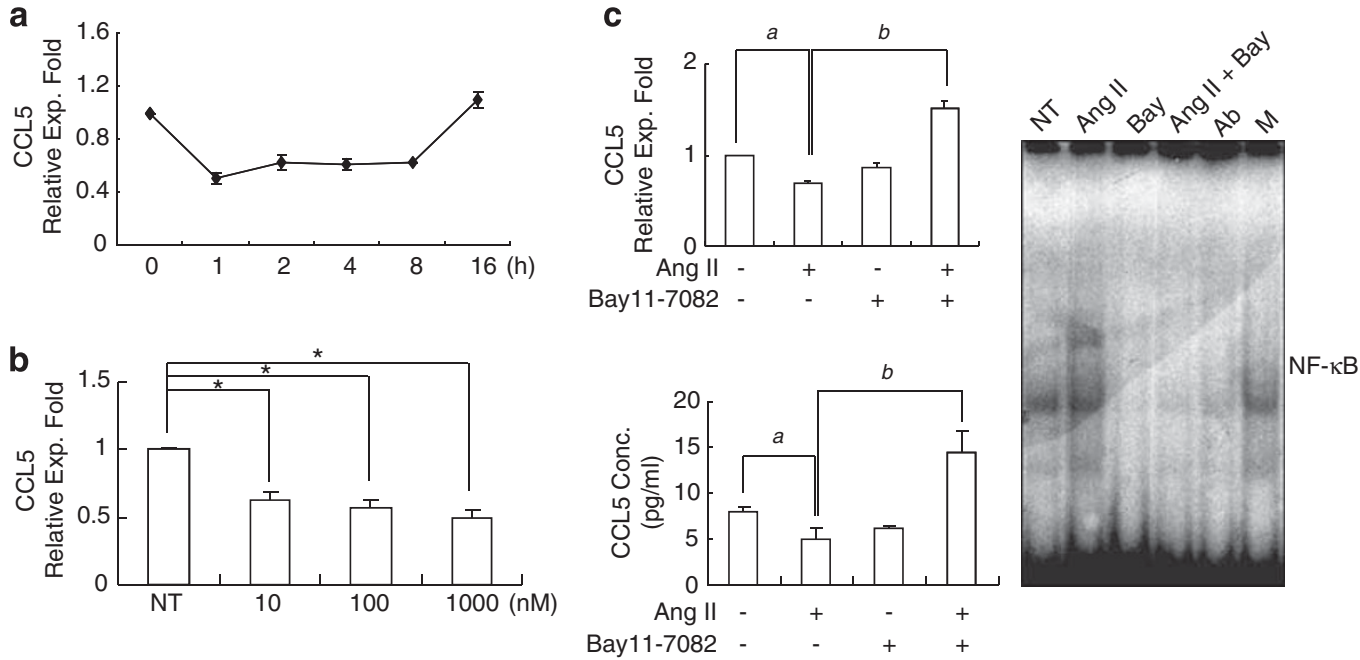

Figure 2 Time course and dose response of CCL5 mRNA inhibition by Ang II in SHR VSMCs, and inhibitory action of Ang II on CCL5 expression is dependent on NF- $\kappa \beta$ activation in SHR VSMCs. (a) SHR VSMCs were treated with Ang II $\left(0.1 \mu \mathrm{mol} \mathrm{I}^{-1}\right)$ for the indicated times and the total RNA was analyzed by real-time PCR. Symbols represent means \pm s.e.m. from three independent experiments. (b) SHR VSMCs were treated or not treated (NT) with 10 , 100 or $1000 \mathrm{nmol} \mathrm{I}^{-1}$ of Ang II for $1 \mathrm{~h}$. After total RNAs were isolated, real-time PCR was performed. Bars represent means \pm s.e.m. from three independent experiments. ${ }^{*} P<0.05$ vs. untreated SHR VSMCs. (c) SHR VSMCs were treated or NT with Ang II $\left(0.1 \mu \mathrm{mol} \mathrm{I}^{-1}\right)$ in the absence or presence of Bay11-7082 $(10 \mu \mathrm{m}$, a selective inhibitor of $\mathrm{I} B \mathrm{~B} \alpha)$ for $1 \mathrm{~h}$. After total RNAs and cell supernatants were isolated, real-time PCR and (enzyme-linked immunosorbent assay) were performed. Bars represent means \pm s.e.m. from three independent experiments. ${ }^{a} P<0.05$ vs. untreated SHR VSMCs. ${ }^{b} P<0.05$ vs. SHR VSMCs treated with Ang II. Specific binding activity of NF- $\kappa \beta$ from nuclear extracts was assessed by electrophoretic mobility shift assay (EMSA). Aliquots of the nuclear extract were incubated with a 100-fold excess of the mutant probe (M) or with $2 \mu \mathrm{g}$ of the anti-NF-к $\beta$ antibody (Ab) before EMSA. Bay:Bay11-7082, Data shown are representative of three independent experiments.
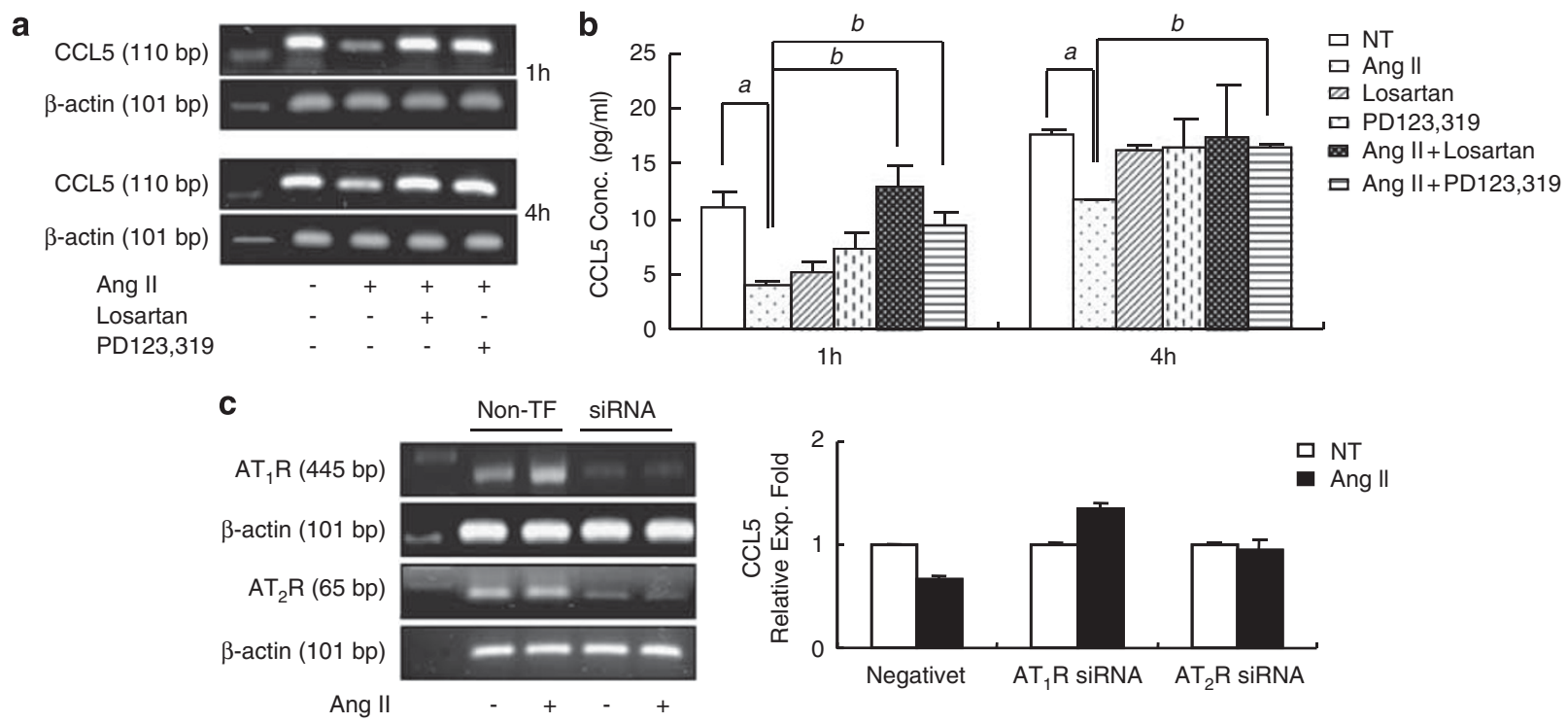

Figure 3 Inhibitory effect of Ang II on CCL5 mRNA expression is related to the both of $A T_{1} R$ and $A T_{2} R$ activation in SHR VSMCs. (a, b) SHR VSMCs were treated or not treated (NT) with Ang II $\left(0.1 \mu \mathrm{mol} \mathrm{I}^{-1}\right)$ in the presence or absence of losartan $\left(\mathrm{AT}_{1} \mathrm{R}\right.$ antagonist, $\left.10 \mu \mathrm{mol} \mathrm{I}^{-1}\right)$ or $\mathrm{PD} 123319\left(\mathrm{AT} \mathrm{R}_{2} \mathrm{R}\right.$ antagonist, $10 \mu \mathrm{mol} \mathrm{I}^{-1}$ ) for 1 or $4 \mathrm{~h}$. After total RNAs and cell supernatants were isolated, reverse transcriptase-PCR and (enzyme-linked immunosorbent assay) were performed. Data shown are representative of three independent experiments. Bars represent means \pm s.e.m. from three independent experiments. ${ }^{a} P<0.05$ vs. untreated SHR VSMCs. ${ }^{b} P<0.05$ vs. SHR VSMCs treated with Ang II. (c) SHR VSMCs were plated on 24 -well plates, grown to $90 \%$ confluence and then transfected with $\mathrm{AT}_{1} \mathrm{R}$ or $\mathrm{AT}_{2} \mathrm{R}$ siRNA oligomers $\left(50 \mathrm{nmol} \mathrm{I}^{-1}\right)$. Transfected or non-transfected SHR VSMCs were then treated or NT with Ang II $(0.1 \mu$ mol I-1) for $1 \mathrm{~h}$. Total RNAs were analyzed by reverse transcriptase-PCR to confirm successful transfection, Real-time PCR was then performed. Bars represent means \pm s.e.m. from three independent experiments. The data are representative of three independent experiments.

losartan and PD123319 (Figure 3a) and the CCL5 levels increased to the CCL5 levels observed in the supernatant of untreated cells (Figure 3b). To further confirm these results, real-time PCR was performed in samples treated with $\mathrm{AT}_{1} \mathrm{R}$ or $\mathrm{AT}_{2} \mathrm{R}$-directed siRNA.
Successful transfection of $\mathrm{AT}_{1} \mathrm{R}$ or $\mathrm{AT}_{2} \mathrm{R}$ siRNA into the SHR VSMCs was observed by reverse transcriptase-PCR and the inhibitory action of Ang II on CCL5 mRNA expression was not detected in SHR VSMCs transfected with $\mathrm{AT}_{1} \mathrm{R}$ or $\mathrm{AT}_{2} \mathrm{R}$ siRNA (Figure $3 \mathrm{c}$ ). 
The inhibitory effect of Ang II on CCL5 expression is mediated by 12 -LO

Ang II is a potent positive regulator of 12-LO expression and activation in porcine and human VSMCs. ${ }^{26,27}$ In a previous study, CCL5 was shown to inhibit Ang II-induced 12-LO expression in SHR VSMCs. ${ }^{25}$ Thus, to examine whether the inhibitory action of Ang II on CCL5 expression was related to 12-LO activation, SHR VSMCs were treated or not treated with Ang II (100 nM) and/or baicalein (a 12-LO inhibitor, $10 \mu \mathrm{M})$ for 1 or $4 \mathrm{~h}$. The inhibitory effect of Ang II on CCL5 mRNA expression was reduced in the presence of baicalein and the protein level of CCL5 increased significantly in the supernatant of cells treated with Ang II and baicalein together (Figure 4a). To further confirm these results, real-time PCR was performed on SHR VSMCs treated with 12LO-directed siRNA. Successful transfection of 12-LO siRNA into SHR VSMCs was observed by reverse transcriptase-PCR and the inhibitory effect of Ang II on CCL5 mRNA expression was not observed in SHR VSMCs that had been treated with 12-LO-directed siRNA (Figure 4b).

The activities of 12-LO and the 12-LO metabolite, 12(S)-hydroxyeicosatetraenoic acid (12(S)-HETE) were shown to be higher in SHR, ${ }^{10,28}$ thus, to further understand the involvement of 12-LO in the inhibition of CCL5 expression in SHR VSMCs by Ang II, the direct effect of 12(S)-HETE on CCL5 expression was examined in SHR
VSMCs. 12(S)-HETE inhibited CCL5 mRNA expression in SHR VSMCs (Figure 4c). In addition, the expression of Ang II-induced 12-LO was decreased by both $\mathrm{AT}_{1} \mathrm{R}$ and $\mathrm{AT}_{2} \mathrm{R}$ inhibitors (Figure $4 \mathrm{~d}$ ).

Inhibitory action of Ang II on CCL5 expression is mediated through MAPK signaling pathways in SHR VSMCs

The role of MAPK signaling pathways in the inhibitory effect of Ang II on CCL5 mRNA expression in SHR VSMCs was also examined. After SHR VSMCs were pretreated with the ERK1/2 inhibitor PD98059 $(10 \mu \mathrm{M})$, the p38 mitogen-activated protein (MAP) kinase inhibitor PD169316 (10 $\mu \mathrm{M})$ or the JNK inhibitor SP600125 $(25 \mu \mathrm{M})$ for $0.5 \mathrm{~h}$, the cells were treated or not treated with Ang II (100 nM) for $1 \mathrm{~h}$. Realtime PCR and (enzyme-linked immunosorbent assay) were then performed. PD98059, PD169316 and SP600125 blocked the inhibitory action of Ang II on CCL5 mRNA expression in SHR VSMCs (Figure 5a). These (enzyme-linked immunosorbent assay) results showed the same patterns that were observed for gene expression (Figure 5b). In addition, to further confirm these results, real-time PCR was performed on SHR VSMCs treated with ERK1/2, p38 or JNK-directed siRNA. Inhibitory effect of Ang II on CCL5 mRNA expression was not observed in SHR VSMCs transfected with ERK1/2, p38 or JNK siRNA (Figure $5 \mathrm{c}$ ).
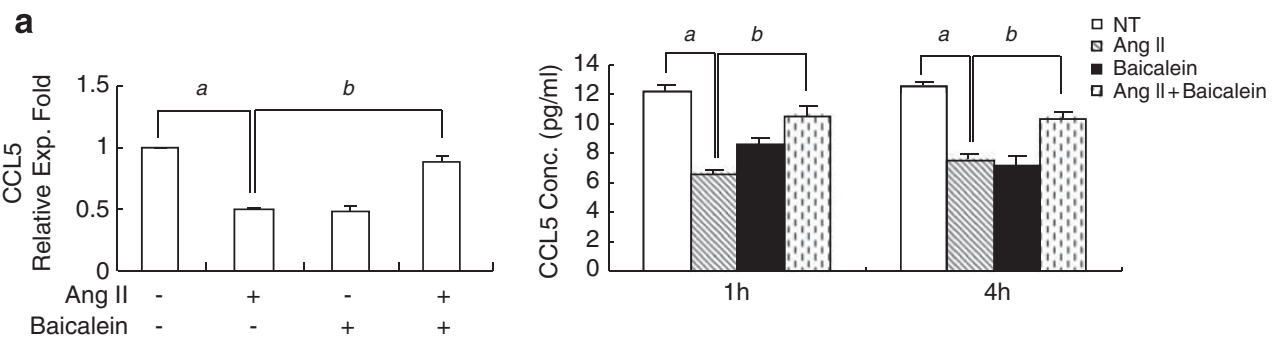

b
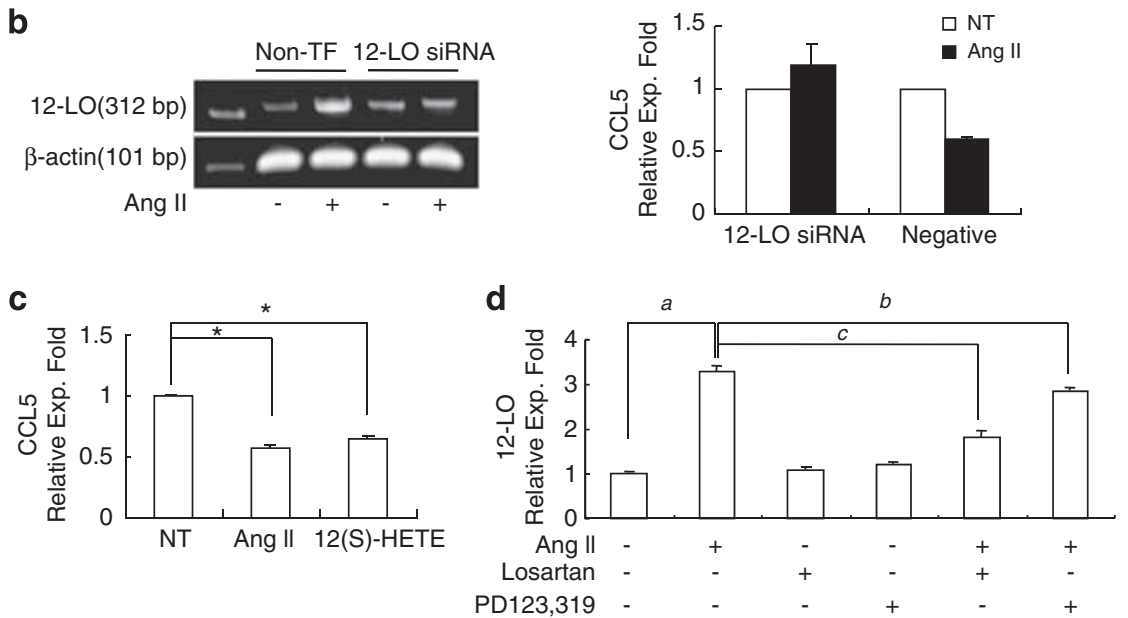

Figure 4 12-LO is involved in the inhibitory action of Ang II on CCL5 expression in SHR VSMCs. (a) SHR VSMCs were treated or not treated (NT) with Ang II $\left(0.1 \mu \mathrm{mol} \mathrm{I}^{-1}\right)$ in the absence or presence of baicalein (12-LO inhibitor, $10 \mu \mathrm{mol} \mathrm{I}{ }^{-1}$ ) for $1 \mathrm{~h}$ (for real-time PCR) or $4 \mathrm{~h}$. After total RNAs and cell supernatants were isolated, real-time PCR and (enzyme-linked immunosorbent assay) were performed. Bars represent means \pm s.e.m. from three independent experiments. ${ }^{a} P<0.05$ vs. untreated SHR VSMCs. ${ }^{b} P<0.05$ vs. SHR VSMCs treated with Ang II. (b) SHR VSMCs were plated on 24-well plates, grown to $90 \%$ confluence and then transfected with 12-LO siRNA oligomers $\left(50 \mathrm{nmol}^{-1}\right)$. Transfected or non-transfected SHR VSMCs were then treated or NT with Ang II $\left(0.1 \mu \mathrm{mol} \mathrm{I}^{-1}\right)$ for $1 \mathrm{~h}$. Total RNAs were analyzed by reverse transcriptase-PCR to confirm successful transfection, real-time PCR was then performed. Bars represent means \pm s.e.m. from three independent experiments. The data are representative of three independent experiments. (c) SHR VSMCs were treated or NT with Ang II $\left(0.1 \mu \mathrm{mol} \mathrm{I}^{-1}\right)$ or $12(\mathrm{~S})$-HETE $(500 \mathrm{~nm})$ for $1 \mathrm{~h}$. After total RNAs were isolated, real-time PCR was performed. Bars represent means \pm s.e.m. from three independent experiments. ${ }^{*} P<0.05$ vs. untreated SHR VSMCs. (d) SHR VSMCs were treated or NT with Ang II $(0.1 \mu$ mol I-1) in the presence or absence of losartan $\left(A T_{1} R\right.$ antagonist, $\left.10 \mu \mathrm{mol} \mathrm{I}^{-1}\right)$ or PD123,319 ( $\mathrm{AT}_{2} \mathrm{R}$ antagonist, $10 \mu \mathrm{mol}^{-1}$ ) for $1 \mathrm{~h}$. After total RNAs were isolated, real-time PCR was performed. Bars represent means \pm s.e.m. from three independent experiments. ${ }^{a} P<0.05$ vs. untreated SHR VSMCs. ${ }^{b} P<0.05$ vs. SHR VSMCs treated with Ang II. ${ }^{c} P<0.01$ vs. SHR VSMCs treated with Ang II. 
a

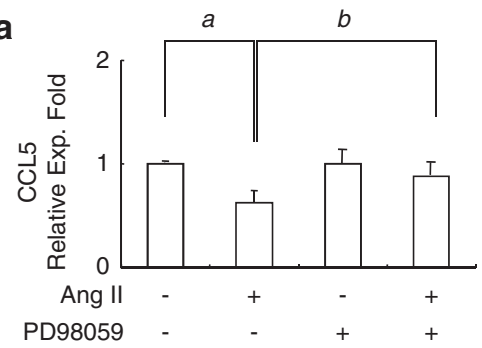

b

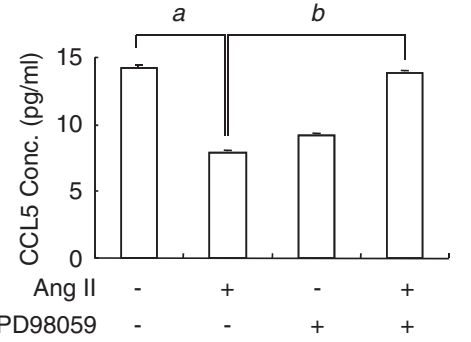

C

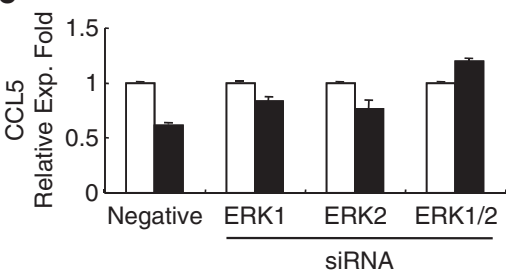

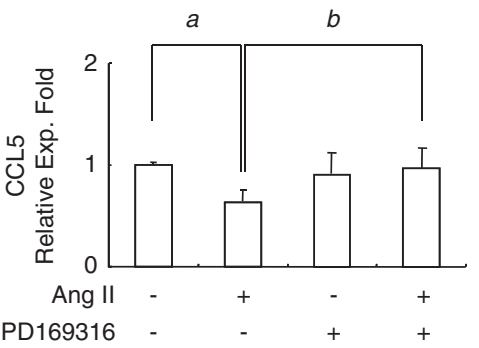
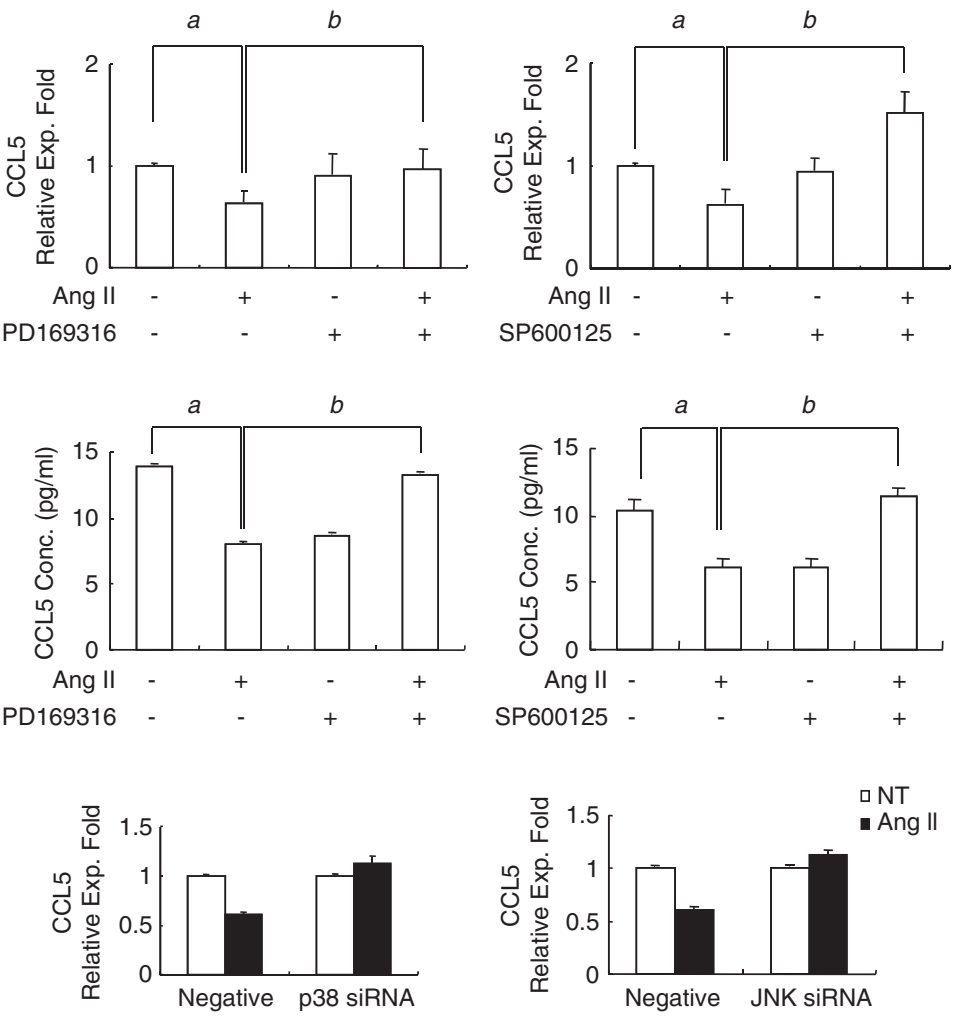

Figure 5 MAP kinases are involved in the inhibitory action of Ang II on CCL5 expression. (a, b) SHR VSMCs were untreated (NT) or pretreated with PD98059 (ERK inhibitor, $10 \mu \mathrm{m}$ ), PD169316 (p38 inhibitor, $10 \mu \mathrm{m}$ ) or SP600125 (JNK inhibitor, $25 \mu \mathrm{m}$ ) for 30 min, and then treated or not treated (NT) with Ang II $\left(0.1 \mu \mathrm{mol}^{-1}\right)$ for $1 \mathrm{~h}$. After total RNAs and cell supernatants were isolated, real-time PCR and (enzyme-linked immunosorbent assay) were performed. Bars represent means \pm s.e.m. from three independent experiments. a $P<0.05$ vs. untreated SHR VSMCs. ${ }^{b} P<0.05$ vs. SHR VSMCs treated with Ang II. (c) SHR VSMCs were plated on 24-well plates, grown to 90\% confluence and then transfected with ERK1, ERK2, ERK1/2, p38 or JNK siRNA oligomers $\left(50 \mathrm{nmolI}^{-1}\right)$. Transfected or non-transfected SHR VSMCs were then treated or NT with Ang II $(0.1 \mu$ mol I-1) for $1 \mathrm{~h}$. Total RNAs were isolated and analyzed by real-time PCR. Bars represent means \pm s.e.m. from three independent experiments.

\section{DISCUSSION}

In naive SHR thoracic aorta tissues, the expression of CCL5 was lower than that in naive WKY thoracic aorta tissues. Although some chemokines are constitutively transcribed and translated, constitutive production of most chemokines is usually low or absent. CCL5 transcription has been known to occur relatively late after the activation of naive cells and is coincident with the upregulation of cytolytic granules in cytotoxic T-cells. ${ }^{29}$ However, CCL5 mRNA is constitutively transcribed and translated in peripheral blood natural killer cells ${ }^{30}$ and the expression of CCL5 mRNA has been observed in naive WKY VSMCs. ${ }^{25}$ Thus, constitutive expression of a chemokine may be dependent on cell type.

In this study, the low expression of CCL5 was demonstrated in SHR thoracic aortic tissues and VSMCs compared with WKY thoracic aortic tissues and VSMCs, and Ang II suppressed CCL5 expression in SHR VSMCs, but not in WKY VSMCs. However, high expression of CCL5 was demonstrated in pulmonary arterial hypertension and the endothelial cells within the pulmonary arterial wall were reported to be a major source of CCL5 production. ${ }^{19}$ Dorfmüller et al. ${ }^{19}$ reported that CCL5 may have a key role in arterial inflammatory processes, such as glomerulonephritis, Kawasaki disease and Takayasu's arteritis, including pulmonary arterial hypertension. Furthermore, Ang II was shown to increase CCL5 expression in rat glomerular endothelial cells from Sprague-Dawley rats and the renal cortex of Wistar rats. ${ }^{2,3}$ Thus, they suggested that Ang II-mediated induction of CCL5 may have an important role in glomerular infiltration of monocytes/macrophages. Wolf et al. ${ }^{3}$ demonstrated that although Ang II increased CCL5 expression in rat glomerular endothelial cells, it did not induce CCL5 mRNA in mesangial cells. These discrepancies could be due to the different cell types and/or different experimental animals or the pleiotropic action of Ang II as a vasoactive cytokine. ${ }^{7}$

Ang II has two subtype receptors, the $\mathrm{AT}_{1} \mathrm{R}$ and the $\mathrm{AT}_{2} \mathrm{R}$, and the density of the $\mathrm{AT}_{2} \mathrm{R}$ is lower than that of the $\mathrm{AT}_{1} \mathrm{R}$ in VSMCs. ${ }^{31} \mathrm{Ang}$ II has been reported to increase $\mathrm{AT}_{1} \mathrm{R}$ expression in SHR VSMCs, but Ang II was shown to only slightly affect $\mathrm{AT}_{2} \mathrm{R}$ expression in SHR VSMCs. ${ }^{8} \mathrm{AT}_{1} \mathrm{R}$ mediates the major stimulatory actions of Ang II, including vasoconstriction, cell proliferation, aldosterone secretion and sodium retention. ${ }^{32}$ In contrast, $\mathrm{AT}_{2} \mathrm{R}$ has been reported to antagonize the vascular actions of $\mathrm{AT}_{1} \mathrm{R}$. However, several studies have reported growth and proinflammatory actions of $\mathrm{AT}_{2} \mathrm{R}$ in VSMCs. ${ }^{31,33,34}$ Moreover, a positive role of the $\mathrm{AT}_{2} \mathrm{R}$ in Ang IIinduced CCL5 expression has been demonstrated in rat glomerular endothelial cells and the rat renal cortex. ${ }^{2,3}$ The inhibitory action of CCL5 on Ang II-induced 12-LO expression is also mediated through $\mathrm{AT}_{2} \mathrm{R}$ in SHR VSMCs. ${ }^{25}$ In this study, the inhibition of CCL5 expression by Ang II in SHR VSMCs was found to be mediated through both $\mathrm{AT}_{1} \mathrm{R}$ and $\mathrm{AT}_{2} \mathrm{R}$ activation.

Ang II is a potent positive regulator of 12-LO expression and proliferation in porcine and human VSMCs. ${ }^{26,27}$ The activities of 12-LO and the 12-LO metabolite 12(S)-HETE are increased in 


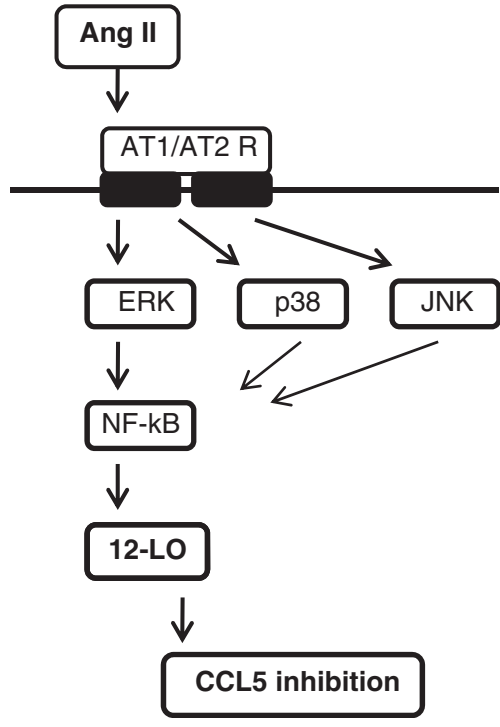

Figure 6 Flow diagram of the action of Ang II on CCL5 inhibition in SHR VSMCs.

SHR, ${ }^{10,28}$ and many studies have demonstrated that $12-\mathrm{LO}$ and $12(\mathrm{~S})-$ HETE have an important role in the pathogenesis of hypertension. ${ }^{10,28,35,36}$ This study demonstrated that the inhibitory action of Ang II on CCL5 expression in SHR VSMCs was mediated through 12LO activation. Ang II did not inhibit CCL5 expression in 12-LO siRNA-transfected SHR VSMCs. In addition, the 12-LO metabolite, 12(S)-HETE directly inhibited CCL5 expression in SHR VSMCs. Moreover, the expression of Ang II-induced 12-LO mRNA was decreased by both $\mathrm{AT}_{1} \mathrm{R}$ and $\mathrm{AT}_{2} \mathrm{R}$ inhibitors. Taken together, these results suggest that activation of Ang II receptors by Ang II leads to the expression of 12-LO, which then acts to inhibit CCL5 in SHR VSMCs. Namely, the lower expression of CCL5 in SHR VSMCs compared with WKY VSMCs is likely because of the activity of 12-LO in SHR VSMCs.

Vascular structural changes in Ang II-induced hypertension are associated with cell proliferation and increased deposition of inflammatory cells and extracellular matrix components. Mechanisms underlying these processes are not still clear; however, the role of MAP kinases may be important. Ang II stimulates the activation of MAP kinases, including ERK1/2, p38 and JNK in VSMCs. ${ }^{31,37,38}$ Ang IIinduced ERK1/2 and p38 activation is increased in SHR vasculature ${ }^{39}$ and ERK1/2 and p38 activation have important roles in Ang IIinduced VSMCs proliferation..$^{37,40,41}$ In these previous studies, the downregulatory effect of CCL5 on Ang II-induced SHR VSMCs proliferation was mediated by inactivation of $\mathrm{p} 38,{ }^{25}$ and the expression of CXCL 8 by Ang II was mediated by ERK1/2 MAP kinase activation. ${ }^{8}$ A potent JNK-activating effect of Ang II was demonstrated in rat aortic cells including VSMCs. ${ }^{40}$ Glomerular JNK activity was shown to be increased in Ang II-induced hypertension ${ }^{42}$ and cardiac JNK was found to be activated more sensitively than ERK1/2 in Ang II-induced hypertension. ${ }^{43}$ However, Touyz et al. ${ }^{39}$ reported that Ang II has no effect on JNK phosphorylation in SHR or WKY VSMCs. This discrepancy may be due to the relative distribution of Ang II receptors, where the density of the $\mathrm{AT}_{2} \mathrm{R}$ is lower than that of the $\mathrm{AT}_{1} \mathrm{R}$ in VSMCs, ${ }^{31}$ namely, Ang II-induced JNK activation occurs through $\mathrm{AT}_{2} \mathrm{R}$. Another reason for this discrepancy may be the different experimental reaction times; namely, JNK activation by Ang II is slower than ERK1/2 and p38 activation. ${ }^{44,45}$ In this study, all three
MAPK signaling pathways were shown to be involved in the inhibitory action of Ang II on CCL5 mRNA expression in SHR VSMCs. The inhibitory effect of Ang II on CCL5 mRNA expression was blocked in SHR VSMCs transfected with ERK1/2, p38 or JNK siRNA.

These combined results indicate that the inhibitory action of Ang II on CCL5 expression was mediated by the 12-LO pathway through the activation of both $\mathrm{AT}_{1} \mathrm{R}$ and $\mathrm{AT}_{2} \mathrm{R}$ and was associated with MAP kinases, ERK1/2, p38 and JNK, pathways in SHR VSMCs (Figure 6). In SHR VSMCs, CCL5 downregulates Ang II-induced 12-LO expression and VSMCs proliferation ${ }^{25}$ and has an upregulatory effect on DDAH-1 expression, which is a regulator of nitric oxide activity (data not shown). On the other hand, Ang II suppresses CCL5 production through 12-LO activity in SHR VSMCs. Taken together, CCL5 is more likely to have a negative role at some stages, but not a positive role as an inflammatory chemokine, in Ang II-induced vascular hypertension.

\section{CONFLICT OF INTEREST}

The authors declare no conflict of interest.

1 Han Y, Runge MS, Brasier AR. Angiotensin II induces interleukin- 6 transcription in vascular smooth muscle cells through pleiotropic activation of nuclear factor-kB transcription factors. Circ Res 1999; 84: 695-703.

2 Kashiwagi M, Musutani K, Shinozaki M, Hirakata H. MCP-1 and RANTES are expressed in renal cortex of rats chronically treated with nitric oxide synthase inhibitor. Involvement in macrophage and monocyte recruitment. Nephron 2002; 92: 165-173.

3 Wolf G, Ziyadeh FN, Thaiss F, Tomaszewski J, Caron RJ, Wenzel U, Zahner G, Helmchen $\mathrm{U}$, Stahl RA. Angiotensin II stimulates expression of the chemokine RANTES in rat glomerular endothelial cells. Role of the angiotensin type 2 receptor. J Clin Invest 1997: 100: 1047-1058.

4 Liao TD, Yang XP, Liu YH, Shesely EG, Cavasin MA, Kuziel WA, Pagano PJ, Carretero $\mathrm{OA}$. Role of inflammation in the development of renal damage and dysfunction in angiotensin II-induced hypertension. Hypertension 2008; 52: 256-263.

5 Marchesi C, Paradis R, Schiffrin EL. Role of the rennin-angiotensin system in vascular inflammation. Trends Phamacol Sci 2008; 29: 367-374.

6 Pan $Q$, Yang $\mathrm{XH}$, Cheng $\mathrm{YX}$. Angiotensin II stimulates MCP-1 production in rat glomerular endothelial cells via $\mathrm{NAD}(\mathrm{P}) \mathrm{H}$ oxidase-dependent nuclear factor-kappa $\mathrm{B}$ signaling. Braz J Med Biol Res 2009; 42: 531-536.

7 Ruiz-Ortega M, Lorenzo O, Suzuki Y, Ruperez M, Egido J. Proinflammatory actions of angiotensins. Curr Opin Nephrol Hypertens 2001; 10: 321-329.

8 Kim HY, Kang YJ, Song IH, Choi HC, Kim HS. Upregulation of interleukin-8/CXCL8 in vascular smooth muscle cells from spontaneously hypertensive rats. Hypertension 2008; 31: 515-523.

9 Ishibashi M, Hiasa KI, Zhao Q, Inoue S, Ohtani K, Kitamoto S, Tsuchihashi M, Sugaya T, Charo IF, Kura S, Tsuzuki T, Ishibashi T, Takeshita A, Egashira K. Critical role of monocyte chemoattractant protein-1 receptor CCR2 on monocyte in hypertension-induced vascular inflammation and remodeling. Circ Res 2004; 94: 1203-1210.

$10 \mathrm{Kim}$ JH, Kang YJ, Kim HS. IL-8/CXCL8 upregulates 12-lipoxygenase expression in vascular smooth muscle cells from spontaneously hypertensive rats. Immune Netw 2009; 9: 106-113.

11 Capers IV Q, Alexander RW, Lou P, Leon HD, Wilcox JN, Ishizaka N, Howard AB, Robert Taylor W. Monocyte chemoattractant protein-1 expression in aortic tissues of hypertensive rats. Hypertension 1997; 30: 1397-1402.

12 Alexander RW. Hypertension and the pathogenesis of atherosclerosis: oxidative stress and the mediation of arterial inflammatory response: a new perspective. Hypertension 1995; 25: 155-161.

13 Dai Q, Xu M, Yao M, Sun B. Angiotensin AT1 receptor antagonists exert antiinflammatory effects in spontaneously hypertensive rats. Br J Pharmacol 2007; 152: 1042-1048.

14 Rodríguez-Iturbe B, Vaziri ND, Herrera-Acosta J, Johnson RJ. Oxidative stress, renal infiltration of immune cells and salt-sensitive hypertension: all for one and one for all. Am J Physiol 2004; 286: 606-616.

15 Dhungana S, Sharrack B, Woodroofe N. Cytokines and chemokines in idiopathic intracranial hypertension. Headache 2009; 49: 282-285.

16 Navrtilova Z. Polymorphisms in CCL2\&CCL5 chemokines/chemokine receptors genes and their association with diseases. Biomed Pap Med Fac Univ Palacky Olomouc Czech Repub 2006; 150: 191-204.

17 Jordan NJ, Watson ML, Williams RJ, Roach AG, Yoshimura T, Westwick J. Chemokine production by human vascular smooth muscle cells: modulation by $\mathrm{IL}-13 . \mathrm{Br} J$ Pharmacol 1997; 122: 749-757.

18 Schall TJ, Bacon K, Toy KJ, Goeddel DV. Selective attraction of monocytes and $T$ lymphocytes of the memory phenotype by cytokine RANTES. Nature 1990; 347: 669-671. 
19 Dorfmüller P, Zarka V, Durand-Gasselin I, Monti G, Balabanian K, Garcia G, Capron F, Coulomb-Lherminé A, Marfaing-Koka A, Simonneau G, Emilie D, Humbert M. Chemokine RANTES in severe pulmonary arterial hypertension. Am J Respir Crit Care Med 2002; 165: 534-539.

20 Zoja C, Donadelli R, Colleoni S, Figliuzzi M, Bonazzola S, Morigi M, Remuzzi G. Protein overload stimulates RANTES production by proximal tubular cells depending on NF-kB activation. Kidney Int 1998; 53: 1608-1615.

21 Shahrara S, Park CC, Temkin V, Jarvis JW, Volin MV, Pope RM. RANTES modulates TLR4-induced cytokine secretion in human peripheral blood monocytes. J Immunol 2006; 177: 5077-5087.

22 Tripathy D, Thirumangalakudi L, Grammas P. RANTES upregulation in the Alzheimer's disease brain: a possible neuroprotective role. Neurobiol Aging 2010; 31: 8-16.

23 Chen XL, Tummala PE, Olbrych MT, Alexander RW, Medford RM. Angiotensin II induces monocyte chemoattractant protein-1 gene expression in rat vascular smooth muscle cells. Circ Res 1998; 83: 952-959.

24 Ruiz-Ortega M, Ruperez M, Lorenzo O, Esteban V, Blanco J, Mezzano S, Egido J. Angiotensin II regulates the synthesis of proinflammatory cytokine and chemokines in the kidney. Kidney Int Suppl 2002; 82: 12-22.

$25 \mathrm{Kim}$ JH, Kim HS. Downregulation of angiotensin II-induced 12-Lipoxygenase expression and cell proliferation in vascular smooth muscle cells from spontaneously hypertensive rats by CCL5. Korean J Physiol Pharmacol 2009; 13: 385-392.

26 Natarajan R, Gu JL, Rossi J, Gonzales N, Lanting L, Xu L, Nadler J. Elevated glucose and angiontensin II increase 12-lipoxygenase activity and expression in porcine aortic smooth muscle cells. Proc Natl Acad Sci USA 1993; 90: 4947-4951.

$27 \mathrm{Kim} \mathrm{JA}, \mathrm{Gu} J \mathrm{~L}$, Natarajan R, Rerliner JA, Nadler JL. A leukocyte type of 12lipoxygenase is expressed in human vascular and mononuclear cells: evidence for upregulation by angiotensin II. Arterioscler Thromb Vasc Biol 1995; 15: 942-948.

28 Sasaki M, Hori MT, Hino T, Golub MS, Tuck ML. Elevated 12-lipoxytenase activity in the spontaneously hypertensive rat. Am J Hypertens 1997; 10: 371-378.

29 Ortiz BD, Nelson PJ, Krensky AM. Switching gears during T-cell maturation: RANTES and late transcription. Immunol Today 1997; 18: 468-471.

30 Kumar D, Hosse J, Toerne C, Noessner E, Nelson PJ. JNK MAPK pathway regulates constitutive transcription of CCL5 by human NK cells through SP1 ${ }^{1}$. J Immunol 2009; 182: $1011-1020$

31 El Mabrouk M, Touyz RM, Schiffrin EL. Differential Ang II-induced growth activation pathways in mesenteric artery smooth muscle cells from SHR. Am J Physiol Heart Cir Physiol 2001; 281: 30-39.

32 Wolf G. Neilson EG. From converting enzyme inhibition to angiotensin II receptor blockade: new insight on angiotensin II receptor subtypes in the kidney. Exp Nephrol 1996; 4: 8-19.
33 Gallinat S, Busche S, Raizada MK, Sumners C. The angiotensin II type 2 receptor: an enigma with multiple variations. Am J Physiol 2000; 278: 357-374.

34 Wolf G, Wenzel U, Burns KD, Harris RC, Stahl RAK, Thaiss F. Angiotensin II activates nuclear transcription factor-kB through AT1 and AT2 receptors. Kidney Int 2002; 61 : 1986-1995.

35 Gonzalez-Nunez D, Claria J, Rivera F, Poch E. Increased levels of 12(S)-HETE in patients with essential hypertension. Hypertension 2001; 37: 334-338.

36 Nozawa K, Tuck ML, Golub MS, Eggena P, Nadler JL, Stern N. Inhibition of the lipoxygenase pathway reduces blood pressure in renovascular hypertensive rats. $\mathrm{Am} \mathrm{J}$ Physiol 1990; 259: 1774-1780.

37 Lee HM, Lee CK, Lee SH, Roh HY, Bae YM, Lee KY, Lim J, Park PJ, Park TK, Lee YL, Won KJ, Kim B. p38 mitogen-activated protein kinase contributes to angiotensin IIstimulated migration of rat aortic smooth muscle cells. J Pharmacol Sci 2007; 105: 74-81.

38 Touyz RM, Mabrouk ME, He G, Wu XH, Schiffrin EL. Mitogen-activated protein/ extracellular signal-regulated kinase inhibition attenuates angiotensin II-mediated signaling and contraction in spontaneously hypertensive rat vascular smooth muscle cells. Cire Res 1999; 84: 505-515.

39 Touyz RM, He G, El Mabrouk M, Diep Q, Mardigyan V, Schiffrin EL. Differential activation of extracellular signal-regulated protein kinase $1 / 2$ and p38 mitogen activated-protein kinase by AT1 receptors in vascular smooth muscle cells from Wistar-Kyoto rats and spontaneously hypertensive rats. J Hypertens 2001; 19: 553-559.

40 Viedt C, Soto U, Krieger-brauer HI, Fei J, Elsing C, Kubler W, Kreuzer J. Differential activation of mitogen-activated protein kinase in smooth muscle cells by angiotensin II: involvement of p22phox and reactive oxygen species. Arterioscler Thromb Vasc Biol 2000; 20: 940-948.

41 Zhao Y, Song HJ, Yun SH, Chae YJ, Jia H, Kim CH, Ha TS, Sachinidis A, Ahn HY, Davidge ST. Inhibition of angiotensin II-induced vascular smooth muscle cell hypertrophy by different catechins. Korean J Physiol Pharmacol 2005; 9: 117-123.

42 Hamaguchi A, Kim S, Yano M, Yamanaka S, Iwao H. Activation of glomerular MAP kinases in Ang II-mediated hypertension. J Am Soc Nephrol 1998; 9: 372-380.

43 Yano M, Kim S, Izumi Y, Yamanaka S, Iwao H. Differential activation of cardiac c-Jun amino terminal kinase and ERK in Ang II-mediated hypertension. Circ Res 1998; 83: 752-760.

44 Takahashi E, Berk BC. MAP kinases and vascular smooth muscle function. Acta Physiol Scand 1998; 164: 611-621.

45 Schmitz U, Berk BC. Ang II signal transduction: stimulation of multiple MAP kinase pathways. Trends Endocrinol Metab 1997; 8: 261-266. 